\title{
The Structure and Delivery of Police Use of Force Training: A German Case Study
}

\author{
Mario S. Staller ${ }^{1}$ D $\cdot$ Swen Koerner ${ }^{2}$. Valentina Heil ${ }^{3}$. Isabel Klemmer ${ }^{1}$. \\ Andrew Abraham ${ }^{4}$. Jamie Poolton ${ }^{4}$
}

Received: 30 January 2021 / Accepted: 30 April 2021 / Published online: 17 May 2021

(c) The Author(s) 2021

\begin{abstract}
The current study aims to investigate the current structure and delivery of police recruit training. Using a case study approach, we systematically observed a semester of police training that consisted of $30 \mathrm{~h}$ with a specific focus on police use of force training. Field notes and time-on-task data was analysed using an inductive approach. The results revealed, first, a lack of constructive alignment of the training modules and learning tasks within the training settings. Second, an adherence to traditional linear approaches to training resulting in high amounts of augmented instruction and feedback and a one-size-fits all approach to technical and tactical behaviour. Third, a non-efficient use of available training time with low amounts of engagement in representatively designed tasks that stimulated problem-solving processes. Based on these results we suggest that there is a need: (a) for police trainers and curriculum designers to align the objectives, practice structure and delivery of police training with the needs of police officers in the field (e.g. conflict resolution); (b) for police trainers to employ more learner-centred pedagogical approaches that account for individual action capabilities and resources, and allow for high amounts of training time with representatively designed training tasks; and (c) for senior managers of overall police training decision-makers to provide the necessary trainer education, in order to furnish trainers with the knowledge and tools to appropriately plan, deliver and reflect upon their practice in keeping with concept of constructive alignment.
\end{abstract}

Keywords Police training · Firearms training - Tactical training $\cdot$ Representative learning design $\cdot$ Coaching $\cdot$ Constructive alignment

Mario S. Staller

mario.staller@hspv.nrw.de

Extended author information available on the last page of the article 


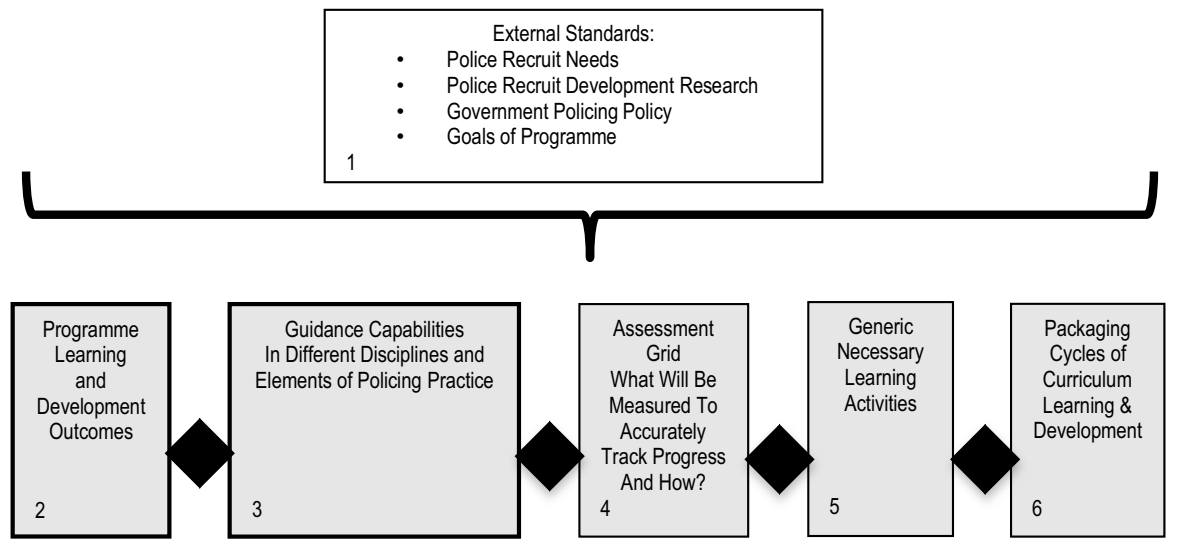

Fig. 1 A schematic of the process to develop a constructively aligned programme (Adapted from Abraham et al. 2015)

\section{Introduction}

Generating and applying the best available evidence to police policy, practice and decision-making is an integral constituent in the process towards the professionalisation of the police (Brown et al. 2018; Mitchell and Lewis 2017). However, in the context of police training, research has indicated that practice based on tradition rather than empirical evidence is common (Basham 2014; Birzer 2003; Cushion 2020). At the same time, research findings have brought into question the effectiveness of police training in conveying the skills needed for conflict management (Jager et al. 2013; Renden et al. 2015a). This has led to efforts to show how empirical evidence might inform the content and delivery of police training on order to further professionalize practice within this domain (Körner and Staller 2018). Researchers in the field of coaching and education have proposed constructive alignment as one way of drawing in empirical findings in a structured and coherent way (Abraham et al. 2015; Biggs 1996; Loughlin et al. 2020). Constructive alignment can be operationalised at a macro programme level and at a micro session delivery level. Figure 1 displays a schematic of how constructive alignment operates at a programme level.

This process offers a guide to programme designers to match and align all elements of design, planning, delivery, assessment with the overarching realityinformed learning outcomes (Abraham et al. 2015; Muir et al. 2015). In addition to this programme level view on constructive alignment, a sessional level view also exists (see Fig. 2). Here, alignment is considered in terms of the connectivity between session outcomes and overall outcomes, and then in terms of the connectivity between desired session outcomes, task/practice design, coach/trainer behaviour and learner engagement. Instructor expertise and effectiveness is evaluated with reference to what they do and their capacity to rationalise why this is constructively aligned. Ultimately, the point of constructive alignment is to facilitate the development of desired skills and, where relevant, the transfer of skills from a training setting to a real-life setting (Loughlin et al. 2020). 


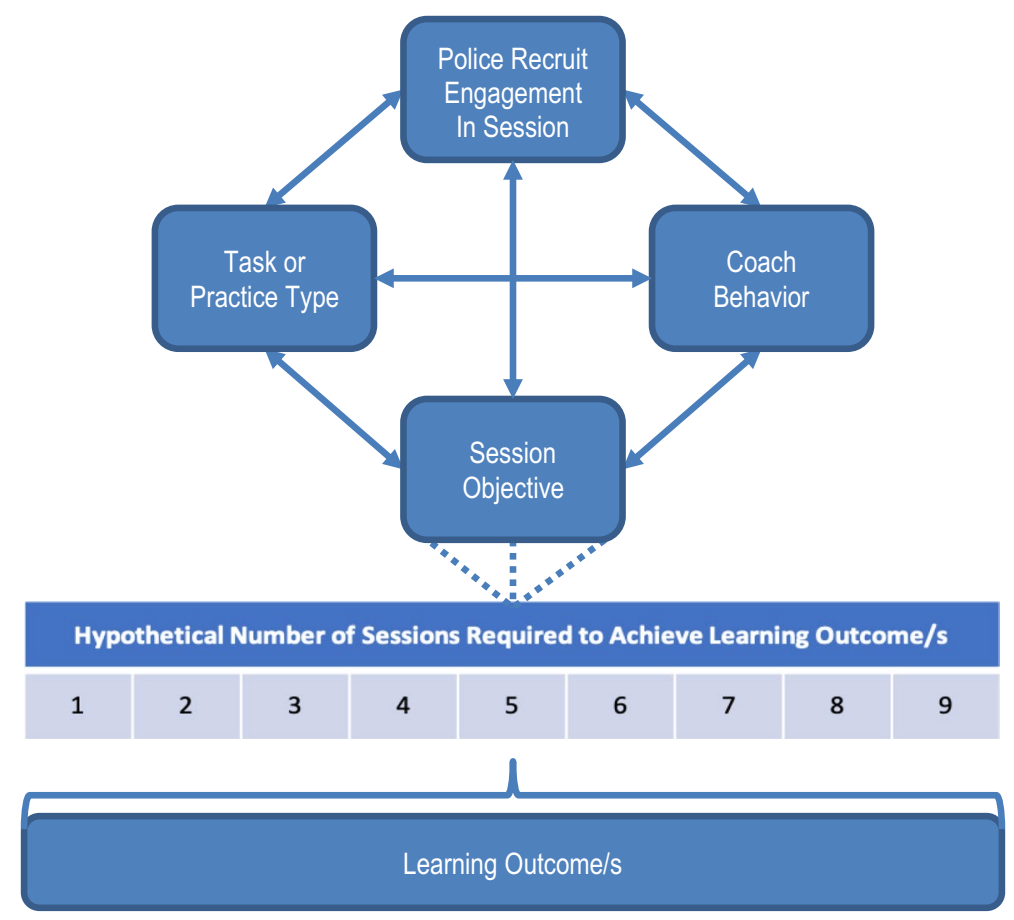

Fig. 2 Session constructive alignment (Adapted from Abraham et al. 2015)

Our focus in this paper is on police use of force training and its constituent components (e.g. firearms training, arrest and self-defence training, etc.) rather than the whole programme of police development. Concerning training programmes for coping with physical conflict situations, empirical studies have begun to paint a picture of the range of skills needed to deal with such situations (Preddy et al. 2019b; Rajakaruna et al. 2017) and to different formats of delivery (Renden et al. 2016). Yet, besides analysis of police self-defence and arrest training (Cushion 2020), there is no known holistic account of the delivery of police training. In order to fill this gap, this paper aims to evaluate the delivery of police training by taking a snap shot of practice in a German police force and drawing on the concept of constructive alignment as a framework for evaluation.

In keeping with this view, it is of concern that research has indicated that skills learned in police training do not necessarily transfer to the criterion environment of dealing with violent encounters (Jager et al. 2013; Renden et al. 2015a). Proposals to tackle this observed lack of transfer, regularly include improving organizational structures to provide more training time (Buttle 2007; Jager et al. 2013; Renden et al. 2015a); revising what is taught (Renden et al. 2015a; Renden et al. 2016) and how it is taught (Cushion 2020; Körner and Staller 2018; Nota and Huhta 2019; Staller and Zaiser 2015). Research so far has mostly investigated the structure and delivery of police training by interviewing trainee officers (Buttle 2007; Rajakaruna et al. 2017) and trainers (Körner et al. 2019; Preddy et al. 2019b). Only recently 
did Cushion (2020) provide empirical evidence about the actual delivery of police training. Using a case study approach and employing participant observation, interviews and time-on-task analysis, Cushion participated and observed three, two-day courses of officers' safety training in the UK. The study showed that practice activities were delivered in a disjointed fashion and were not representatively designed. This adds empirical evidence to the notion that police training methods regularly seem to employ an instructor-centric linear teaching model (Birzer 2003; Werth 2011). This approach is characterized by having defined the relevant conditions and stimuli under which the learner has to perform, and comparing the performance of the learner with a clear description of criteria by which the behaviour will be judged acceptable (Elias and Merriam 2005). The underlying assumption of linear teaching is that skills can be isolated and built part by part in preparation for the criterion environment. The focus in this process is on a specific technique and sequence of movements, which must be copied from the trainer's model and reproduced in the event of an emergency (Körner and Staller 2018). For example, Cushion (2020) observed that police trainers delivering officer safety training drew heavily from a manual of arrest and self-defence techniques to design their programme. Advantages of linear approaches include accelerated acquisition of isolated skills in low-stress and low variance environments, which is accompanied by the learner (and teachers) subjective conviction of technique mastery (Abraham and Collins 2011). However, such learning environments (low-stress, low-variance) do not usually align to the specific situational parameters of conflict situations in the policing context (Jager et al. 2013; Renden et al. 2015a) which should characterise the learning outcomes of police training (Cushion 2020; Rajakaruna et al. 2017). More representative task design in this context should consist of two components: (a) functionality of the task; and (b) action fidelity (Pinder et al. 2011). While the functionality of a training activity enables the trainee to experience the pressure conditions and constraints of the task expected in the criterion context, action fidelity refers to the learner being afforded the full range of responses available in the field. The core element of representativeness is the relationship between perceptual-cognitive, motor and emotional conditions (Broadbent et al. 2015; Headrick et al. 2015; Staller et al. 2017a, b) and which seem to be underrepresented in police training (Cushion 2020; Körner et al. 2019).

Another drawback of the linear approach to learning often lies in limiting the amount of time that learners are actually engaged in practice, due to the adherence to blocked practice drills with augmented coach instruction and feedback (CurtnerSmith et al. 2001; Renshaw and Moy 2018). In the context of police training, Cushion (2020) noted that the available training time was not maximised. Over the three courses observed participants spent $54.1 \%$ of the training time being passive, while the coach(es) demonstrated, briefed the learners and gave feedback. After taking into account all activities in which participants observed others or worked as a simulator, the time spent motorically engaged in subject matter-related tasks was between 20 and 30\%. Time-on-task is a necessary factor for the mastering of skills (Ericsson 2016) and considered a process indicator for learning (Mars 2006). However, it is acknowledged that activity alone is not enough. Learners need to be engaged and invested in the task at hand (Christenson et al. 2012) to advance the rate of 
learning. As such, police training needs to engage police recruits in well-designed learning activities (Cushion 2020; Staller and Zaiser 2015). Taken together, linear approaches to training may come at the expense of the representative design of the training tasks and the low time-on-task of the learner.

Although the literature is critical of the structure and delivery of police training, empirical investigation of how training is actually delivered is limited to the perspective of the trainees (learners) and coaches (trainers) (i.e. Preddy et al. 2019a; Rajakaruna et al. 2017 and to a specific component of police training (i.e., officer safety training, Cushion 2020). Furthermore, when generalising the findings of police training it is important to be cognisant of differences in national socio-economic context. With these limitations in mind, the current study utilised a case study approach employing participant observation to investigate the structure and delivery of police training in Germany and how it is configured to deliver its outcomes.

\section{Methods}

A case study methodology was implemented employing participant observation to systematically garner enough information about police training to effectively understand how it was delivered (Cushion 2020; Thomas 2011) Participant observation is a frequently applied field strategy in learning settings (Patton 1990) and is deemed appropriate for case study designs where the phenomenon under investigation is observable in the natural environment, suitable information can be collected via this means, and the boundaries of investigation are open-ended (Jorgensen 2015). Ethical approval for the study was obtained by the Ethics Committee of the German Sports University of Cologne.

\subsection{Data Collection}

Data collection was conducted at a police academy in Hesse, Germany. A study section with 5 full days of police use of force training provided the analytical frame of the study with the object being the process of training (Thomas 2011). The study section was part of the second year of the recruits' training and contained $30 \mathrm{~h}$ of police training and instruction with one weekly training day dispersed over 5 consecutive weeks. The study section was embedded between two sections of practical training out in the field at a functioning police department. A curriculum of the to be learned skills and competencies provided the framework for the police training. In general, the goal of police education at the University of Applied Sciences of Police and Public Administration is to develop the competencies needed for fulfilling the tasks of policing (Hessisches Ministerium des Innern und für Sport 2016). The stated learning outcomes and curriculum for police use of force training are to develop recruits' individual self-defence concept and being able to apply the learned technical and tactical skills in scenario-based exercises (Hessische Hochschule für Polizei und Verwaltung 2016). During the 5 training days, aspects of self-defence, restraint and control, shooting and tactical training were covered. 




Fig. 3 Structure of observed training days with additional information regarding content, training facility, number of coaches, participants and observing researchers, respectively

A class of 24 recruits and their trainers were observed during training sessions. The group of 24 was split in two for most sessions; in total 25 trainer-recruit delivery sessions were observed (see Fig. 3). Participants of police training were informed about the observation in advance of the sessions taking place and provided 
their informed consent. Several individuals were absent over the course of the study causing attendance rates to differ in each training session. The number of coaches also differed depending on the training days and the delivered content. The ratio of coaches-to-recruits varied over the five days from 2:7 (day 5; firearms training) to 1:24 (day 1; self-defence, arrest and control training). The variation in numbers are outlined in Fig. 1.

Four researchers (MS, SK, VH, IK) monitored the training as observer participants. Three researchers (MS, SK, IK) had more than 10 years of experience in teaching self-defence and combat related training programmes. All researchers took extensive field notes in addition to a "time-on-task" analysis.

In order to account for the microstructure of the training, a time-on-task analysis (Cushion 2020) was employed. For this purpose, the timing, content and duration of each training element was. In keeping with the sessional basis of constructive alignment researchers paid specific attention to what the tasks participants were engaging with (e.g., training activities, listening, pairs, groups, alone) and what coaches were doing (e.g., demonstrating, giving instruction). Session objectives were drawn from the learning outcomes noted in the introduction. This enabled the recording of the type and the duration of each element along with the pedagogy employed by the coaches.

The microstructure of each session was noted at $15 \mathrm{~s}$ intervals. Additionally, for every interval researchers noted what the learners were doing and how the specific training activity was set up. This included information about group size (e.g., one learner and three simulators) and a precise description of the exercise.

\subsection{Data Analysis}

Following the data collection phase, curriculum, session plans, field notes and timeon-task analysis were compared between the two observers within a team. Differences in the raw data were resolved by discussing the issues in question until agreement about the observation was achieved. The analytic process consisted of two distinct phases and followed the protocol employed by Cushion (2020). First, the collected raw data (field notes, time-on-task analysis) was broken down into "meaning units" that conveyed one idea or a related set of observations. All field notes were examined line-by-line as well as data concerning the time frame of each activity within training sessions. Second, meaning units identified were grouped together to organise common meaning units into lower-order themes. A further level of interpretation compared lower-order themes to organise them into larger more inclusive higher-order themes.

Concerning the time-on-task analysis, an inductive approach was employed, utilising the process of abstraction to reduce and group the raw data. the inductive approach resulted in two themes relating to the training activities that were carried out. First, practice activities that focused on reproducing the behaviour demonstrated and instructed by the coach. These activities were concerned with "how" to perform a specific technical or tactical skill and involved no decision concerning "what" skill to use. Second, "problem solving" activities included practice that aimed at solving 
Table 1 Table of themes

\begin{tabular}{ll}
\hline Higher order theme & Lower-order theme \\
\hline Structure of police training & Macrostructure of police training \\
& Microstructure of the training sessions \\
Content and delivery & $\begin{array}{l}\text { Prominent focus on the use of force } \\
\text { Disconnected modules of training } \\
\text { Lack of representativeness }\end{array}$ \\
& $\begin{array}{l}\text { Simulators } \\
\text { Non-representative task design } \\
\text { Differences between technical performance and } \\
\text { performance under representative circum- } \\
\text { stances }\end{array}$ \\
\end{tabular}

a given task under certain constraints involving "what"-and "how"-decisions. In order to account for training activities with different level of participation and different roles (observer, simulator, player), a player-index was used to calculate net training time from total training time within a specific activity. The player-index was based on the group size and number of individuals that performed as a player and of those who performed as simulators or observers. For example, when a training activity consisted of 4 recruits, comprising 1 player and 3 simulators, a player index of 1:4 was noted. Net training time was then calculated by multiplying total training time for this activity with the player index. If the recorded training time for this activity was $4 \mathrm{~min}$, a net training time of $1 \mathrm{~min}$ was calculated $(4 \mathrm{~min} \times 1 / 4=1 \mathrm{~min})$.

\section{Results}

The higher and lower order themes that emerged from the data analysis are presented in Table 1. The higher order themes are presented in subsequent paragraphs.

\subsection{Structure of Police Training}

On a macrolevel, training was divided into the three different training settings of self-defence and arrest training, firearms training and tactical training. The total time-on-task analysis showed that recruits spent the most time participating in tactical training and the least training time on firearms training (see Table 2).

On a microlevel, cumulatively recruits engaged in almost $9 \frac{1 / 2}{2}$ hours $(M=09: 29: 00)$ of practice activities directly related to developing their technical and problem-solving skills. Of this time, short of $4 \mathrm{~h}(M=03: 52: 28)$ was spent as a player (net training time) reproducing techniques and tactics that were demonstrated by the coaches $(M=02: 28: 24)$ or problem solving $(M=01: 24: 04)$. The percentage of time-on-task as a player (net training time) in each training setting was largest for self-defence and arrest training $(M=23.13 \%)$ and at similar levels for firearms $(M=15.04 \%)$ and tactical $(M=13.89 \%)$ training. 


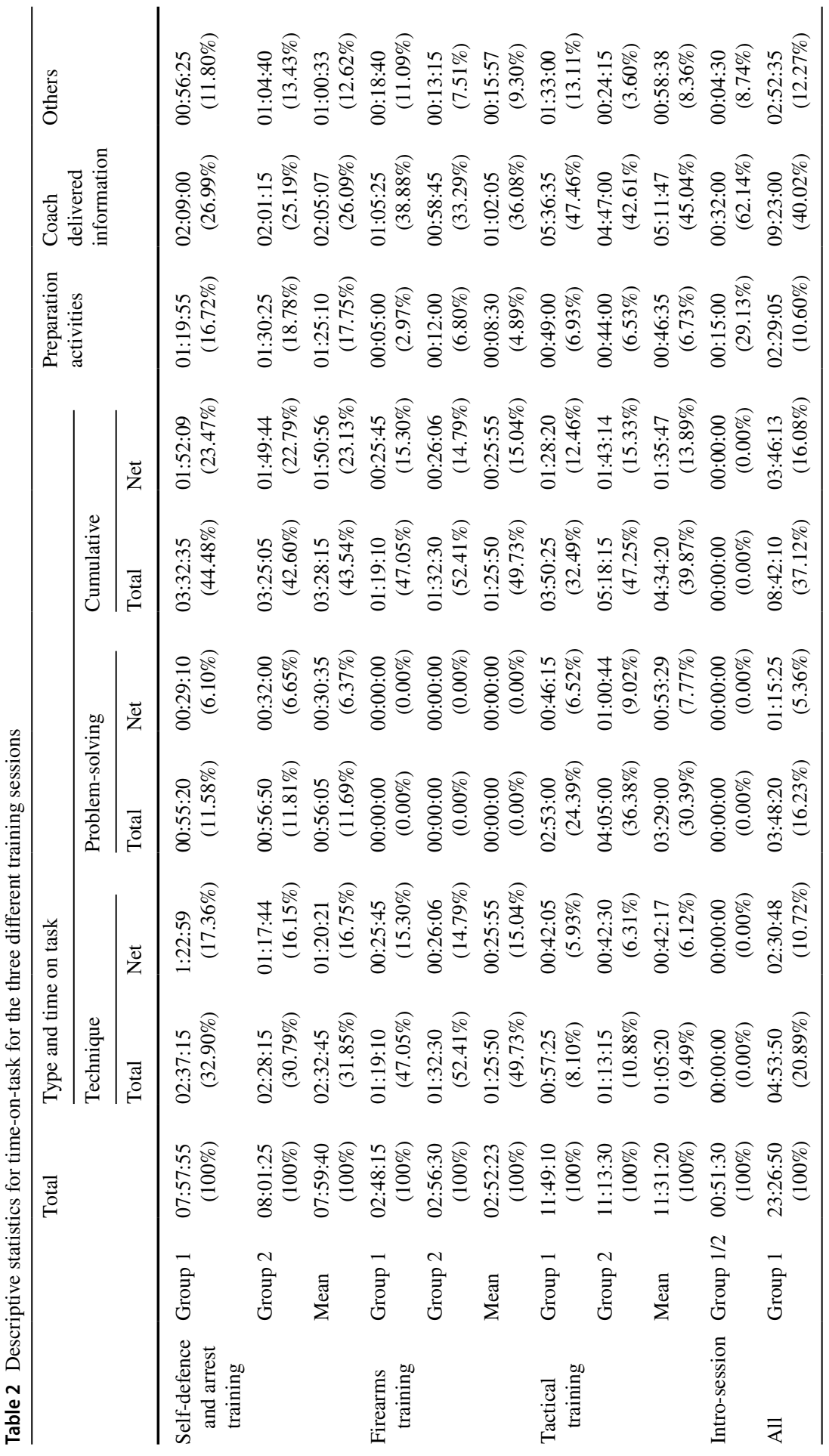




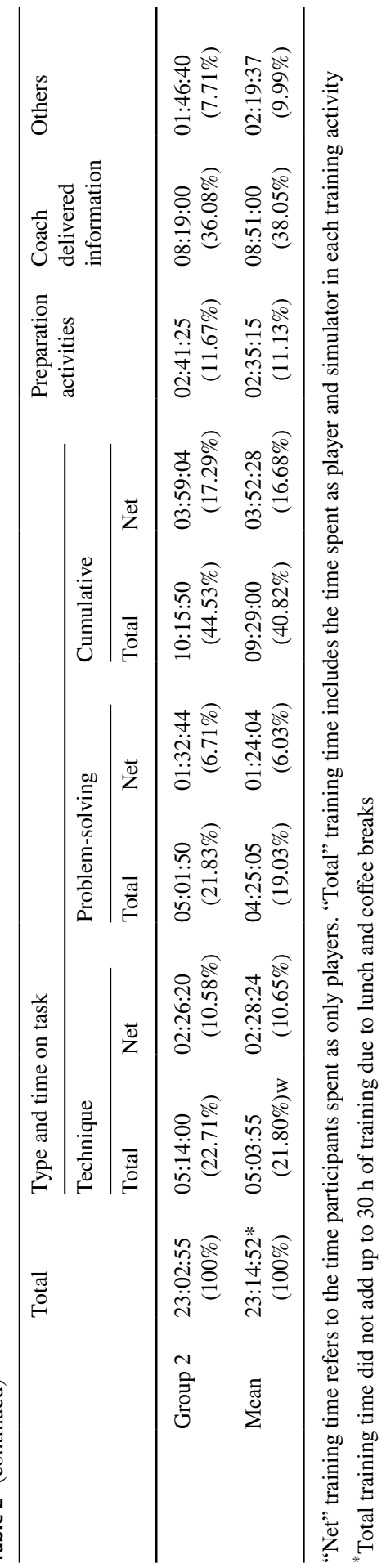


Net training time, spent in training activities including problem solving accounted for on average of $6.37 \%$ in self-defence and arrest training, $0.00 \%$ in firearms training and $7.77 \%$ in tactical training. Coach Delivered Information activities accounted for nearly $9 \mathrm{~h}(M=08: 51: 00)$ of training time with Instruction $(M=13.62 \%)$ and Feedback $(M=11.54 \%)$ the main activities (see Table 3$)$.

Concerning the time spent in different training sessions, results revealed that most total training time was spent in tactical training $(M=11: 31: 20)$. However, the net training time of each participant in tactical training was less $(M=01: 35: 47)$ than in self-defence, arrest and control training $(M=01: 50: 56)$, but more than in firearms training $(M=00: 25: 55)$.

\subsection{Content and Delivery}

The analysis of the curriculum and the session plans and the observation of training yielded two main findings. First, there was a prominent focus on the management of conflict by the means of force. Only one brief simulation in the five training days aimed at resolving a conflict by communicative means. Second, there was a lack of connection between the different modules of police training, namely selfdefence and arrest training, firearms training and tactical training. At a macrolevel, the modules appeared disjointed, in the sense that one element did not inform or was not deliberately integrated within another. At a microlevel, there appeared a disconnect in the topics (skills) covered within a single training session. An example was observed in self-defence and arrest training:

The training goes from defending against grabs to the wrist, to applying arm bars, joint locks and handcuffing. In the end, the recruits had to do a relay race with a partner, where they had to handcuff a person who was already stood against the wall. (Field notes, day 5, self-defence and arrest training)

\subsection{Lack of Representative Task Design}

A prominent feature of the police training observed was the lack of representativeness. A common observation was that simulators in training tasks lacked the presentation of valid information for the learner to act upon. Especially in activities involving the delivery of blows and strikes, simulators seemed afraid of what the player (key learner) was about to do. As a result, attacks on the learner were slow and nonaggressive:

Recruits have to stop a charging attacker and to perform a takedown and to arrest the person. The simulators do not attack properly and players perform the technique at the wrong distance. Another technique would be more appropriate at this "wrong distance". It looks like a choreography. The simulator did not resist and helped the learner by going down even if the technique was performed at the wrong distance. (Field notes, day 2, self-defence and arrest training) 


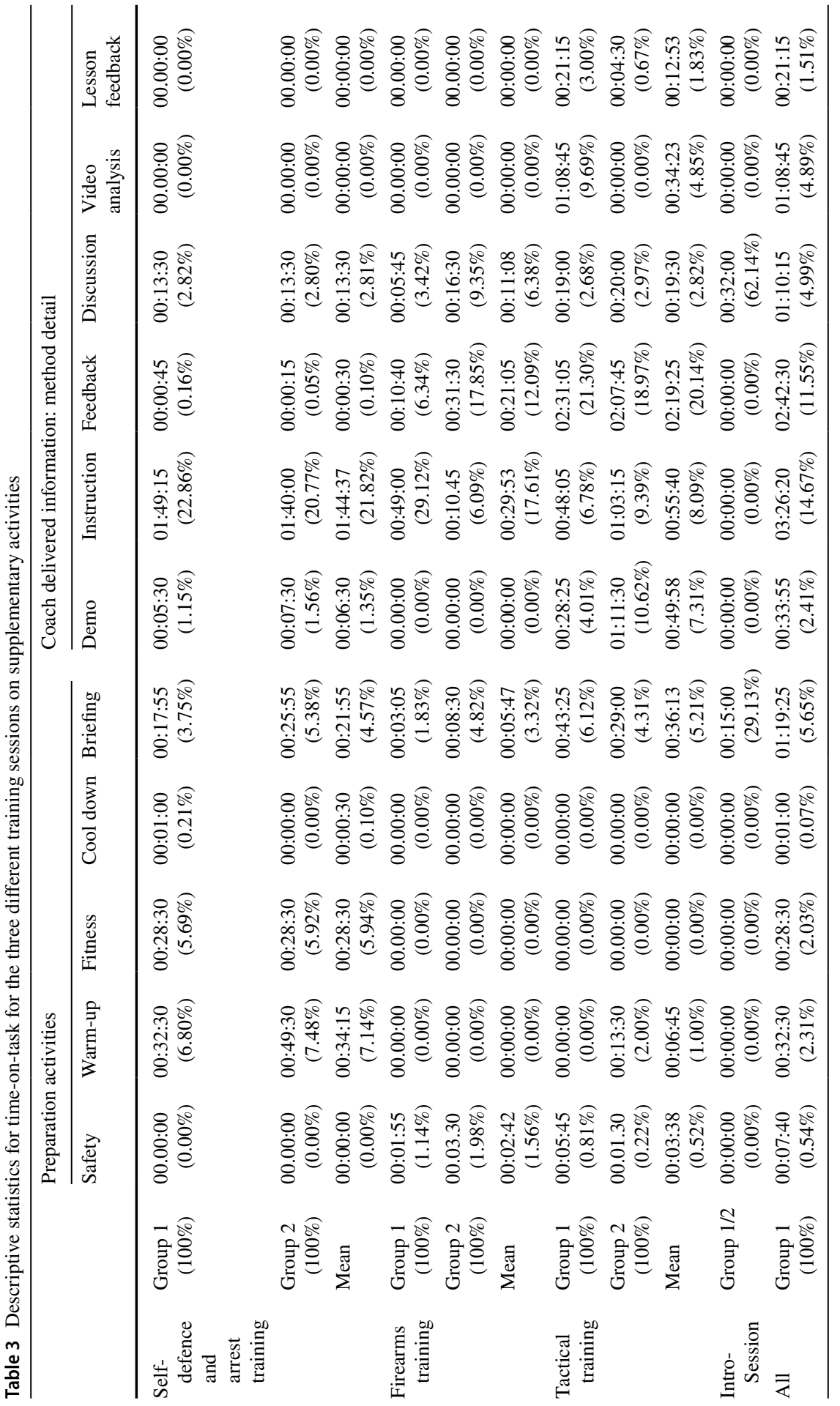




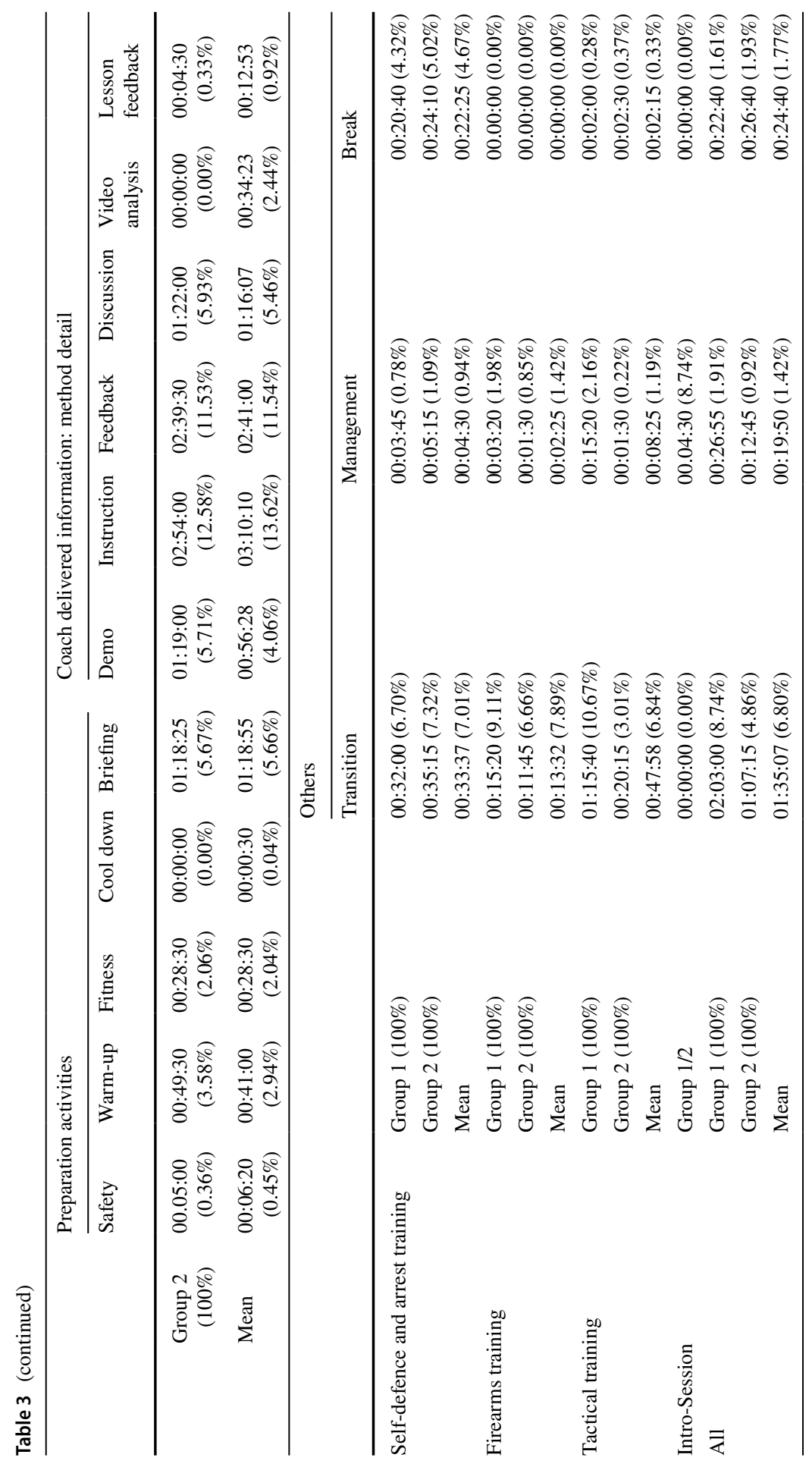


As illustrated, such activities mostly resulted in non-representative interactions, which lacked valid feedback for the learner. The coaches did not explicitly instruct the simulator about how to act or intervene during the activity to adapt or optimise the simulator behaviour. There were a lot of training tasks that lacked representativeness by design of the training task:

Teams of five competed against each other in a relay race. Four recruits laid on the floor, their hand behind their backs. One recruit had to handcuff everyone - and releasing the handcuffs before handcuffing the next partner. The partners on the ground helped the recruit who was working, because every team wanted to be the fastest team. Each round lasted for approx. 2 minutes. So every recruits laid down 4 times for 2 minutes and worked once for 2 minutes. They all laughed and had a lot of fun during this exercise. (Field notes, day 5, self-defence and arrest training).

In this example, the task itself was designed in a non-representative way, with five recruits lying next to each other waiting for being handcuffed. Learners rushed from one person to another order to be the fastest team. As such, recruits were not able to perform the behaviour as it would be needed in the field. This lack of action fidelity could also be observed in firearms training. For example, recruits were tasked with math problems before shooting.

Participants were in ready position and had to shoot the target the coach was calling out. Targets were geometrical objects with numbers in it. The coach said: "yellow 1" or "blue 3". Recruits shoot two rounds at the specified target. In the next exercise the coach set a calculation task: "Square root of 9" - Recruits had to shoot a the " 3 ". All shooting tasks did not involve a representative stimulus. (Field notes, day 3 , firearms training)

In the field, like in this practice activity, police officers have to react to specific information sources, however, the information is context specific, unlike this activity. In tactical training, paper targets were used to represent suspects in a "enter and search" practice activity.

In tactical training recruits were presented with a scenario (possible burglary in progress), which they (teams of two) had to respond to. The two recruits had to enter safely the premises and search for the suspect. The coaches hid paper targets (picturing a man holding a gun) in the apartment. Recruits had to talk to the paper targets (e.g. "Drop your gun!"). After the scenario the two recruits talked among themselves. [Recruit A] said: "That was good. We have to do this more often". [Recruit B] answered: "I find it difficult to practice with those paper targets. They don't react”. (Field notes, day 5, tactical training)

Furthermore, due to official restrictions on tactical training involving simulators with guns, recruits knew in advance that coaches would not shoot at them, making the scenario predictable and likely reducing the anxiety levels within learners (Nieuwenhuys et al. 2012). As such, the task was less representative. 
One team was performing a scenario (entering a building after a potential burglary); the others observed. One recruit said "Nobody is shooting at you" (the coaches are not allowed to shoot at the recruits in that kind of training); The other recruit replied: "Then it's not that bad". (Field notes, day 4, tactical training)

Performance of recruits also varied between isolated technical training activities compared to those that allowed for the integration of information and action. Whereas recruits seemed to perform quite well during technical training-that is, they applied the technique according to the instruction and feedback of the coachthey were not able to apply the trained technique to a more representative setting later in training. Instead, the recruits found different individual solutions to the problem set:

Recruits were taught a controlling technique on the ground. After 15 minutes of technical training with corrections from the coach, recruits should team up and fight against each other with one being the suspect and the other being the officer trying to control and arrest the partner. Recruits were not able to apply the taught technique. Every recruit tried different solutions to control the opponent. Some succeeded, some not. But nobody maintained the shown position longer than a few seconds. (Field notes, day 3, self-defence and arrest training)

\section{Discussion}

The current study fits into efforts to professionalize police training in Germany (Körner et al. 2018). With a focus of these efforts to provide evidence for the reflection of current practices, the aim of this body of work is to provide empirical evidence about the actual delivery of police training and how it is configured to deliver its outcomes. The observation and the data analysis provided insights into the actual practice of police training in a German law enforcement agency. Similar to the themes presented in the results section, the discussion will focus on (a) the structure and delivery of police training, (b) the level of representativeness in police training.

\subsection{The Structure and Delivery of Police Training}

The macrostructure of police training seems to lack a consistent rationale that is grounded in functional skill development and constructively aligned with the objective of developing competent police officers. Furthermore, police training seems to adhere to a traditional, linear structure both on a macro- (isolated training elements) and a micro-level (isolated techniques and tactics). Finally, the current microstructure of police training provides recruits with a relatively small percentage of training time actually engaged in practice focused activities, especially involving problemsolving skills. 


\subsubsection{Lack of a Consistent Rationale for the Structure of Police Training}

The overall structure of police training is built around providing solutions to conflict situation problems. For the solving of operational problems with weapons, recruits engage in firearms training. In order to be able to solve conflict without the use of weapons, recruits participate in self-defence and arrest training. The integration of these elements can sometimes be seen in tactical training, when scenarios are employed as training activities. However, often the focus of such sessions is not firearms and/or self-defence, but the teaching of tactical behaviour like situational awareness and the enter and searching of apartments. This structure around solutions of conflict situations can be found in other states at a national level (Hochschule der Sächsischen Polizei 2016; Hochschule des Bundes für öffentliche Verwaltung 2015) as well as in other countries at an international level (Cushion 2020; Renden et al. 2015 b). This is problematic, insofar that (a) tasks are isolated from the context in which they occur and (b) taught content may not be aligned with the needs of the learners and their working context.

Decontextualizing practice in order to develop understanding and rules how to solve specific problems is useful on a temporary basis (Price et al. 2019). However, the lack of context may lead to the practice of disintegrated, "off-the-shelf" solutions (Cushion 2020) and the lack of functional task alignment (i.e. learners do not act on the actual information that is present in the field) when designing representative learning tasks (Pinder et al. 2011). As such, it may be advisable to structure the training content around problems, like citizen-police interaction, terror intervention or domestic violence interventions instead of physical coercion, de-escalation or the use of firearms. Focusing on problems instead of distinct solutions (e.g. use of force, arrest techniques, de-escalation) would allow learners to use their individual capabilities and conflict resolutions strategies (Körner and Staller 2018; Rutter 2020). This approach is supported by data from scenario training in police agencies, where the same problems are solved differently by men and women according to their own capabilities (Jaeckle et al. 2019). A problem-based approach would also compliment the ecological dynamics perspective advocating the developing of skills based on the action capabilities of the performer and the task at hand (Seifert et al. 2019).

The type and characteristics of the problems set should be based on a need analysis of the taught officers, which may vary depending on the specific context they will operate in. In keeping with box 1 in Fig. 1, constructive alignment of the learning program should be based around intended learning objectives that have been informed by the demands of the working context to be entered and the needs of the recruits relative to those demands. This becomes the basis for designing long-, medium-, and short-term plans that will enable these objectives to be achieved and that provide a key reference point from which police trainers and decision-makers can monitor and adjust the effectiveness of their programs, plans and delivery (Abraham et al. 2015). Our interpretation of the course curriculum and our practice observations suggest that the macrostructure of the programme was not obviously guided by a clear view of what recruits should be expected to cope with at this point in their training. Instead, a specific set of skills was selected seemingly on received wisdom. Such an approach appears to limit the curriculum designers and 
coaches' perspective of police training. Coping with operational situations-which are often conflictual in nature (Ellrich and Baier 2016; Hine et al. 2016)—demands more than the use of use of force, tactical behaviour and shooting skills (Todak and James 2018; Todak and White 2019; Zaiser and Staller 2015). Communication and de-escalation skills were not part of the police training in the study section observed. The lack of training activities focusing on communication and de-escalation skills has been criticized by trainees of Australian police forces (Rajakaruna et al. 2017). As such, police training would benefit from more clearly aligning the structure of the programme and its delivery with the intended outcome of police recruits being able to cope with conflict.

\subsubsection{Traditional, Linear Structure and Delivery of Police Training}

It appears that underlying the structure of police training (macrostructure) and the delivery of training (microstructure) is a traditional, linear and reproductive approach to skill acquisition. In this case study, police training was structured at a macro-level into three isolated parts or "modules": self-defence and arrest training, firearms training and tactical training ${ }^{1}$ (Hessische Hochschule für Polizei und Verwaltung 2016). In the domain of policing this siloed approach is known as the applied learning model (Adang 2011), which is common in police educational settings in Germany (Hochschule der Sächsischen Polizei 2016; Hochschule des Bundes für öffentliche Verwaltung 2015). Skills are first practiced in isolated (technical) modules before they are integrated in a scenario training consisting of interactive simulations between learners (players) and role-players (simulators). In the current study, interactive scenario training was carried out during tactical training; however, beyond these examples, representative simulations were scarce. Instead, training was heavily focused on training isolated techniques in a reproductive manner.

The performance difference of recruits in isolated training tasks compared to representatively designed tasks, showed that recruits were not able to apply the formerly learned skills in contextualised environments. This is in line with predictions from both naturalistic decision making (NDM) and ecological dynamics' interpretations of human performance (Seifert et al. 2019). In short, the lack of functional coupling and integration of the different elements (perception, cognition and action, brain and body, use of force and de-escalation) that are needed in order to solve conflicts (Rutter 2020) will inevitably limit the transfer of skills to practice. The approach of isolating modules (firearms training, self-defense and arrest training, tactical training, de-escalation) that are later put together (as a whole) is based on the assumption of "modularity", which is a characterizing feature of the traditional linear approach to learning. The assumption is that isolated processes (e.g., techniques) can be decoupled from the action in the performance context and effectively integrated back into the whole system to advance performance ((Renshaw et al. 2019). However,

\footnotetext{
1 The de-escalation and communications module is not part of police training, instead the subject of Psychology is in charge of teaching the recruits these skills (Hessische Hochschule für Polizei und Verwaltung 2016).
} 
this assumption is not supported by other theoretical rationales, like the NDM and ecological dynamic frameworks (Ashford et al. 2020; Correia et al. 2018; Renshaw et al. 2019; Seifert et al. 2019) which argue that skills are best developed in context.

At a micro-level the results also showed evidence of a traditional linear learning model. These linear models of learning are characterised by: (a) "ideal models" and the existence of single solutions of skills-to-be-learnt (Moy et al. 2016; Orth et al. 2018; Seifert et al. 2019); (b) ideal techniques are demonstrated by the coach and repeated by learners in isolated drills before put into application within the performance context (Metzler 2017; Moy et al. 2014 2016); (c) complex skills are split into smaller parts (Metzler 2017); (d) training consists of highly structured teaching sequences (Moy et al. 2016); and (e) detailed prescriptive instructions and corrective verbal feedback provision by the coach (Correia et al. 2018). Highly structured sequences were observed in the current study, especially in the training of selfdefence and arrest, and firearms. Furthermore, detailed descriptive and prescriptive instructions, as well as corrective feedback were given regularly by the coaches. These findings are consistent with those from studies of police educational settings in general (Shipton 2012; Werth 2011) and police training in particular (Cushion 2020), which also found a high prevalence of teacher-centred linear approaches to learning.

Furthermore, the current curriculum emphasises the existence of ideal models of technical and tactical behaviour in specific situations. As such, the curricular structure suggests a one-size-fits all approach. All recruits, irrespective of their body composition and action capabilities, were expected to learn certain self-defence and arrest techniques. The assumption that one movement pattern acts as an optimal template for all learners has been rejected on an empirical basis (Chow et al. 2009; Schöllhorn 1999; Schöllhorn et al. 2012). Hence, this traditional linear approach lacks in providing the learners with opportunities to develop their individual strategies for dealing with conflict situations. This problem has been addressed recently (Körner and Staller 2018; Rutter 2020; Staller and Körner 2019b), by advocating a more goal-oriented approach to conflict situations, which emphasises the discovery of individualised solutions to problems faced according to the learner's action capabilities and prerequisites. Despite for the most part adopting a linear, there were examples of coaches, especially in self-defence and arrest training and firearms training, attempting to deliver goal-directed tasks that were constrained to guide the practice of context-specific functional solutions.

\subsubsection{Low Amount of Qualitative Time-on-Task}

In the current case study, a relatively low amount of qualitative time-on-task was observed ( $M=40.82 \%$ total activities with practice focus). This is in line with results from Cushion (2020), who also found that officers spent less than $50 \%$ of the training time actively engaged in a task. Since time-on-task is a necessary factor for the mastering of skills (Ericsson 2016) and considered as a process indicator for learning (Mars 2006) police training would benefit from increasing the time-on-task of the learners. 
However, practice per se is not predictive of learning efficacy, since the quality of practice task also plays a fundamental role concerning skill development (Correia et al. 2018). With regards to quality, two aspects have to be considered. First, the amount of practice time, where the learner actually is able to act upon the environmental constraints; that is, the amount of practice time when the learner has the role of the player (and not the simulator). Second, the amount of training time spent engaging in representative simulations; that is, training tasks that incorporate high levels of functionality and action fidelity. As such, training tasks focusing on the technical reproduction of a certain behaviour could be deemed as low-quality interactions. In the current study, time-on-task involving partner interactions that satisfy these two desirable criteria (player-status and no technical reproduction) was approximately $6 \%$ of total training time. Since claims for optimizing police training regularly include the call for more training time (Jager et al. 2013; Renden et al. 2015a), the current results would suggest first optimizing the available training time by developing high quality training tasks (simulations). Tackling this issue would require dealing with two aspects. First, to reduce the high amounts of time recruits spent passive, and second, to optimize the partner interactions in a way that representative simulations can take throughout the learning programme rather than just at the end as is common in a traditional modular approach (Staller and Körner 2019a).

\subsubsection{Representative Learning Design in Police Training}

The results indicated that the levels of representativeness differed across the different training settings. In firearms training, representativeness was lacking by design due to the necessary safety constraints of live fire shooting (Adang 2011; Staller et al. 2017a, b). Instead, numbers, static images or coach instructions served as non-representative cues for initiating a shooting response. In self-defence and arrest training, it was observed that many exercises contained no functional coupling between the information presented and the action of the learner. For example, a training activity was observed which had recruits lying on the ground waiting to get handcuffed rather than talking or taking them down. Moreover, it was observed that recruits acting as attacking simulators charged slowly towards learners, which in turn performed their defending behaviour at a distance, where they did not reach the attacker. However, the attacking partner reacted to the defending behaviour like it was the right distance. The need for recruits to literally act as simulators meant that learners were responding to information that was not likely representative of the information presented by a civilian in the field. This stresses the importance of ensuring optimal partner interaction by developing partners as good simulators by introducing roles and responsibilities of good training partners (Staller and Körner 2018). There is empirical evidence that recruits acting as simulators elicits positive learning effects (Sjöberg et al. 2016), providing an additional argument for shifting the simulator role away from the coaches as the sole simulator.

It was found that tactical training was most representative of the criterion environment when recruits had the opportunity to solve problems posed using scenario training. However, after the coaches gave, often large amounts of, corrective feedback, recruits repeated the same scenario, which now lacked the unpredictability 
and surprise of the first training experience. Such observations indicate that scenario training is not representative by design per se and as such may not be capable of fostering "realism" in training as advocated by the literature (Adang 2011; Murray 2004). Analysing training tasks alongside the framework of representative learning design may prove the more functional alternative in ensuring skill transfer (Krause et al. 2017). Hence the simulations should be representatively designed regardless of their complexity (regular partner interaction vs. high-end scenario training). Practitioners and researchers alike may consider high quality partner interactions as a quality criterion for police training (Staller and Körner 2019a).

It appears that the modularized organizational structure of police training as well as the linear oriented microstructure is geared towards what is regularly called "realistic scenario trainings" (Andersen et al. 2016; Sjöberg and Karp 2012). However, the amounts of training time spent as learners in such tasks was low. Long waiting times seem to have costs concerning valuable training time-on-task. Also, the motivation of learners seems to be negatively affected by long waiting times (Staller et al. 2021). Due to high numbers of recruits compared to the low numbers of coaches that are available, a sustainable solution for this problem may lie in rendering partner interactions with peers as "mini" scenarios, being highly representative simulations that get more and more complex over time and are dependent on the resources that are available.

\subsection{Limitations}

Case study methodology has inherent weaknesses. The current case took place at a specific time period in the education of young police officers, in a specific training institute with a specific focus on police use of force training. Therefore, the results cannot be readily generalised to police training in other law enforcement agencies at a national or international level. As such, further observations of police training for different populations (recruits, regular officers, specialized teams, etc.) in different settings (agencies, states, countries) with different trainers are needed to get a fuller picture of the practice of police training. That being said, since police institutions in Germany have been reluctant of providing access in order to research coaching in police training (Staller and Körner 2019b), the current case study for the first time provides insights into such programs and may serve as a catalyst for further research into the structure and delivery of police training.

\section{Conclusion and Practical Implications}

The current study aimed to shed light on the structure and delivery of police training in Germany and how it is configured to deliver its outcomes. The key point of reference being programme and sessional constructive alignment.

From a macro programme perspective, our study suggested that problems existed in learning outcome design and subsequent programme design. We noted a lack of realism in connecting the learning outcomes around what recruits were expected to 
overcome and the demands of the role they would fulfil in the field. At face value the outcomes of having a self-defence concept and being able to apply the learned technical and tactical skills in scenario-based exercises make intuitive sense. However, we suggest they lack important context and aligned perceptual, cognitive and motor skills. For example, the skill of recognising, communicating and de-escalating with a capacity to adapt behaviour seems to be underrepresented within existing training programmes. Drawing on these ideas, an alternative outcome could read: the recruit will be able to recognise and respond to potential threats of violence in different contexts through means of negotiation and/or physical use of force. In keeping with constructive alignment, such an outcome would give clearer guidance on how this would be assessed, how tasks might be designed and how modules could be connected.

Given the problem of a lack of constructive alignment at a programme level, it is not surprising that we observed a lack of constructive alignment at a sessional level in the training modules. In particular, an adherence to traditional linear approaches to training with high amounts of augmented instruction and feedback was generally observed. This approach typically offers a one-size-fits all approach to technical and tactical behaviour in specific situations, which is at odds with being able to resolve conflictual situations in police-citizen interactions. As such, training programmes and activates could be structured and designed to develop a broader skill set for coping with conflict in the field at the expense of technical training of distinct techniques. We do not completely discount the role of repetitive drills, rather we would suggest that if they are used it is within a spiral curriculum (Harden and Stamper 1999) that layers and returns to the necessary concepts in different contexts. By structuring police training in this spiral fashion, where the main concepts are learned in an iterative and progressive fashion, skill development of police officers could take place on a much more individual level by maintaining the demands posed by the field at each skill level.

Finally, our data suggests that available training time in police training seems not be used efficiently. Active time-on-task, especially engagement in representatively designed tasks, involving problem-solving capabilities was low given that the police literature advocates representatively and interactively designed training tasks as the gold standard for training (Nota and Huhta 2019; Staller and Körner 2019a). Again, this may well be explained by a lack of constructive alignment in the programme, which limits up front planning as there is a lack of a clear learning outcome and, therefore, a clear view on how to achieve that outcome. We noted, in the course of this data collection that police trainers were afforded only a limited amount of time to plan and reflect. While this needs further investigation, a lack of planning time along with a programme that is not constructively aligned could explain much of the issues we have identified here. We are aware that the results here are critical of the trainers we have observed; however, these trainers were experienced and open to observation. We suggest the issues identified are more about limits in original design than in trainer capacity. However, in order to achieve transformations in coach delivery, coach development in police training should expose police trainers to alternative contemporary pedagogical approaches to skill learning. This should include first-hand experience of and reflection on the pedagogical tools available to 
coaches and the teaching of the learning theories underpinning the pedagogy. Likewise, traditional pedagogies and their genesis within the knowledge structure of the coach should be reflected upon, in order to check and challenge current practice (Cushion 2020; Hoy and Murphy 2001).

Authors contribution All authors substantially contributed to the current study and the final manuscript. The study was designed by MS, AA and SK. Data was collected and analysed by MS, SK, VH, IK. MS wrote the first draft of the manuscript. SK, AA and JP provided substantial feedback to the manuscript and helped to reach the manuscript reach its final form.

Funding Open Access funding enabled and organized by Projekt DEAL.

\section{Compliance with ethical standards}

Conflict of interest We have no known conflict of interest to disclose. We would like to thank the expert coaches for participating in the study.

Open Access This article is licensed under a Creative Commons Attribution 4.0 International License, which permits use, sharing, adaptation, distribution and reproduction in any medium or format, as long as you give appropriate credit to the original author(s) and the source, provide a link to the Creative Commons licence, and indicate if changes were made. The images or other third party material in this article are included in the article's Creative Commons licence, unless indicated otherwise in a credit line to the material. If material is not included in the article's Creative Commons licence and your intended use is not permitted by statutory regulation or exceeds the permitted use, you will need to obtain permission directly from the copyright holder. To view a copy of this licence, visit http://creativecommons.org/licen ses/by/4.0/.

\section{References}

Abraham A, Collins DJ (2011) Effective skill development: How should athletes' skills be developed? In: Button A, Richards H (eds) Performance psychology: a practitioners guide, pp 207-229. Churchill Livingstone. https://doi.org/10.1016/b978-0-443-06734-1.00015-8

Abraham A, Sáiz SLJ, Mckeown S, Morgan G, Muir B, North J, Till K (2015) Planning your coaching: a focus on youth participant development. In: Nash CS (ed) Practical sports coaching. Routledge, Milton, pp 16-53

Adang O (2011) Learning to deal with potentially dangerous situations: a situation-oriented approach. In: Haberfeld MR, Clarke CA, Sheehan DL (eds) Police organization and training. Springer, New York, pp 153-168

Andersen JP, Pitel M, Weerasinghe A, Papazoglou K (2016) Highly realistic scenario based training simulates the psychophysiology of real world use of force encounters: implications for improved police officer performance. J Law Enforce 5(4).

Ashford M, Abraham A, Poolton J (2020) A communal language for decision making in team invasion sports. Int Sport Coach J. https://doi.org/10.1123/iscj.2019-0062

Basham BB (2014) Police instructor or police educator? Salus J 2(1):99-109

Biggs J (1996) Enhancing teaching through constructive alignment. Higher Edu 32(3):347-364

Birzer ML (2003) The theory of andragogy applied to police training. Policing Int J Police Strat Manag 26(1):29-42. https://doi.org/10.1108/13639510310460288

Broadbent DP, Causer J, Ford PR, Williams AM (2015) Contextual interference effect on perceptualcognitive skills training. Med Sci Sports Exerc 47(6):1243-1250. https://doi.org/10.1249/mss.00000 00000000530

Brown J, Belur J, Tompson L, McDowall A, Hunter G, May T (2018) Extending the remit of evidencebased policing. Int J Police Sci Manag 20(1):38-51. https://doi.org/10.1177/1461355717750173 
Buttle JW (2007) A constructive critique of the officer safety programme used in England and Wales. Polic Soc 17(2):164-181. https://doi.org/10.1080/10439460701302735

Chow JY, Davids K, Button C, Renshaw I, Shuttleworth R, Uehara L (2009) In: Hopper T, Butler J, Storey B (eds) Nonlinear pedagogy: implications for teaching games for understanding (TGfU), pp 131-144. PHE-Canada.

Christenson SL, Reschly AL, Wylie C (eds) (2012) Handbook of research on student engagement. Springer. https://doi.org/10.1007/978-1-4614-2018-7

Correia V, Carvalho J, Araújo D, Pereira E, Davids K (2018) Principles of nonlinear pedagogy in sport practice. Phys Edu Sport Pedag 24(2):117-132. https://doi.org/10.1080/17408989.2018.1552673

Curtner-Smith MD, Todorovich JR, McCaughtry NA, Lacon SA (2001) Urban teachersí use of productive and reproductive teaching styles within the confines of the national curriculum for physical education. Eur Phys Edu Rev 7(2):177-190. https://doi.org/10.1177/1356336x010072005

Cushion CJ (2020) Exploring the delivery of officer safety training: a case study. Polic J Policy Pract 14(1):166-180. https://doi.org/10.1093/police/pax095

Elias JL, Merriam SB (2005) Philosophical foundations of adult education. Krieger Publications, Malabar

Ellrich K, Baier D (2016) Police officers as victims of violence: findings of a germany-wide survey. In: Baier D, Pfeiffer C (eds) Representative studies on victimisation, pp 139-162. Nomos Verlagsgesellschaft mbH and Co. KG. https://doi.org/10.5771/9783845273679-139

Ericsson KA (2016) Expertise and individual differences: the search for the structure and acquisition of experts' superior performance. Wiley Interdis Rev Cognit Sci. https://doi.org/10.1002/wcs.1382

Harden RM, Stamper N (1999) What is a spiral curriculum? Med Teach 21(2):1-4

Headrick J, Renshaw I, Davids K, Pinder RA, Araújo D (2015) The dynamics of expertise acquisition in sport: the role of affective learning design. Psychol Sport Exe 16:83-90. https://doi.org/10.1016/j. psychsport.2014.08.006

Hessische Hochschule für Polizei und Verwaltung (2016) Modulbuch für den Studiengang Bachelor of Arts "Schutzpolizei” [Module book for the course of studies Bachelor of Arts „Schutzpolizei"]. Hessische Hochschule für Polizei und Verwaltung.

Hessisches Ministerium des Innern und für Sport (2016) Ausbildungs- und Prüfungsordnung für den gehobenen Polizeivollzugsdienst für die Studiengänge Bachelor of Arts Polizeivollzugsdienst „Schutzpolizei“ und „Kriminalpolizei“ (APOgPVD) [Training and examination regulations for the upper level police force for the study Bachelor of Arts Police Force "Schutzpolizei" and "Kriminalpolizei" (APOgPVD)]. Staatsanzeiger Für Das Land Hessen 2016(30):776-792

Hine KA, Porter LE, Westera NJ, Alpert GP (2016) The understated ugly side of police-citizen encounters: situation, suspect, officer, decision-making, and force predictors of officer injuries. Polic Soc 28(6):665-683. https://doi.org/10.1080/10439463.2016.1251430

Hochschule der Sächsischen Polizei (2016) Modulhandbuch für den Studiengang "Bachelor of Arts (B.A.): Polizeivollzugsdienst" im 24. Studienjahrgang (2016/2019) [Module manual for the course of studies "Bachelor of Arts (B.A.): Law Enforcement Service" in the 24th year of study (2016/2019)]. Hochschule der Sächsischen Polizei.

Hochschule des Bundes für öffentliche Verwaltung (2015) Modulhandbuch für den Bachelorstudiengang (B.A.) Kriminalvollzugsdienst im Bundeskriminalamt [Module Manual for the Bachelor's Programme (B.A.) Criminal Justice Service at the Federal Criminal Police Office. Hochschule des Bundes für öffentliche Verwaltung, Fachbereich Kriminalpolizei, Bundeskriminalamt Wiesbaden.

Hoy AW, Murphy PK (2001) Teaching educational psychology to the implicit mind. In: Torff B, Sternberg RJ (eds) Understanding and teaching the intuitive mind, pp 145-184. Lawrence Erlbaum.

Jaeckle T, Benoliel B, Nickel O (2019) Police use of force decisions: a gender perspective. In: Walden University Research Symposium: 2019 Program and Posters, 23. Walden University.

Jager J, Klatt T, Bliesener T (2013) NRW-Studie: Gewalt gegen Polizeibeamtinnen und Polizeibeamte [North Rhine-Westphalian study: Violence against police officers]. Christian-Albrechts-Universität zu Kiel.

Jorgensen DL (2015) Participant observation. In: Scott RA, Kosslyn SM (eds) Emerging trends in the social and behavioral sciences, pp 1-15. Wiley. https://doi.org/10.1002/9781118900772.etrds0247

Körner S, Staller MS (2018) From system to pedagogy: towards a nonlinear pedagogy of self-defense training in the police and the civilian domain. Sec J 31(2):645-659. https://doi.org/10.1057/ s41284-017-0122-1

Körner S, Staller MS, Heil V, Klemmer I, Kecke A (2018) Professionalization in progress: police use of force self-defense training in Germany. Mov J Phys Edu Sport Sci 11(3):102-103 
Körner, S., Staller, M. S., and Kecke, A. (2019). „Es ist ja immer irgendwie eine andere Situation...“ - Konflikt- versus Trainingserfahrungen von Polizist*innen ["It's always some other situation..." - Conflict versus training experiences of police officers]. In: M. Meyer and M. S. Staller (Eds.), "Lehren ist Lernen: Methoden, Inhalte und Rollenmodelle in der Didaktik des Kämpfens": internationales Symposium; 8. Jahrestagung der dvs Kommission "Kampfkunst und Kampfsport" vom 3. - 5. Oktober 2019 an der Universität Vechta; Abstractband (pp. 25-26). Deutsche Vereinigung für Sportwissenschaften (dvs).

Krause L, Farrow D, Reid M, Buszard T, Pinder RA (2017) Helping coaches apply the principles of representative learning design: validation of a tennis specific practice assessment tool. J Sports Sci 5(1):1-10. https://doi.org/10.1080/02640414.2017.1374684

Loughlin C, Lygo-Baker S, Lindberg-Sand Å (2020) Reclaiming constructive alignment. Eur J High Edu. https://doi.org/10.1080/21568235.2020.1816197

Metzler M (2017) Instructional models for physical education. Routledge

Mitchell RJ, Lewis S (2017) Intention is not method, belief is not evidence, rank is not proof: ethical policing needs evidence-based decision making. Int J Emerg Serv 31(3):188-199. https://doi.org/10. 1108/ijes-04-2017-0018

Moy B, Renshaw I, Davids K (2014) Variations in acculturation and Australian physical education teacher education students' receptiveness to an alternative pedagogical approach to games teaching. Phys Edu Sport Pedag 19(4):349-369. https://doi.org/10.1080/17408989.2013.780591

Moy B, Renshaw I, Davids K (2016) The impact of nonlinear pedagogy on physical education teacher education students' intrinsic motivation. Phys Edu Sport Pedag 21(5):517-538. https://doi.org/10. 1080/17408989.2015.1072506

Muir B, Till K, Abraham A, Morgan G (2015) A framework for planning your practice: a coach's perspective. In: Till K, Jones B (eds) The science of sport rugby, pp 161-175. The Crowood Press.

Murray KR (2004) Training at the speed of life, volume one: the definitive textbook for military and law enforcement reality based training. Armiger Publications.

Nieuwenhuys A, Cañal-Bruland R, Oudejans RRD (2012) Effects of threat on police officers' shooting behavior: anxiety, action specificity, and affective influences on perception. Appl Cognit Psychol 26(4):608-615. https://doi.org/10.1002/acp.2838

Nota PMD, Huhta J-M (2019) Complex motor learning and police training: applied, cognitive, and clinical perspectives. Front Psychol 10:167-220. https://doi.org/10.3389/fpsyg.2019.01797

Orth D, van der Kamp J, Button C (2018) Learning to be adaptive as a distributed process across the coach-athlete system: situating the coach in the constraints-led approach. Phys Edu Sport Pedag 24(2):146-161. https://doi.org/10.1080/17408989.2018.1557132

Patton MQ (1990) Qualitative researching. Sage Publications.

Pinder RA, Davids K, Renshaw I, Araújo D (2011) Representative learning design and functionality of research and practice in sport. J Sport Exc Psychol 33:146-155

Preddy JE, Stefaniak JE, Katsioloudis P (2019a) Building a cognitive readiness for violent police-citizen encounters: a task analysis. Perform Improv Quart 5(4):1-22. https://doi.org/10.1002/piq.21288

Preddy JE, Stefaniak JE, Katsioloudis P (2019b) The convergence of psychological conditioning and cognitive readiness to inform training strategies addressing violent police-public encounters. Perform Improv Quart 5(4):1-32. https://doi.org/10.1002/piq.21300

Price A, Collins D, Stoszkowski J, Pill S (2019) Coaching games: comparisons and contrasts. Int Sport Coach J 6(1):126-131. https://doi.org/10.1123/iscj.2018-0015

Rajakaruna N, Henry PJ, Cutler A, Fairman G (2017) Ensuring the validity of police use of force training. Police Pract Res 18(5):507-521. https://doi.org/10.1080/15614263.2016.1268959

Renden PG, Landman A, Savelsbergh GJP, Oudejans RRD (2015a) Police arrest and self-defence skills: performance under anxiety of officers with and without additional experience in martial arts. Ergonomics 58(9):1-11. https://doi.org/10.1080/00140139.2015.1013578

Renden PG, Nieuwenhuys A, Savelsbergh GJP, Oudejans RRD (2015b) Dutch police officers' preparation and performance of their arrest and self-defence skills: a questionnaire study. Appl Ergon 49:817. https://doi.org/10.1016/j.apergo.2015.01.002

Renden PG, Savelsbergh GJP, Oudejans RRD (2016) Effects of reflex-based self-defence training on police performance in simulated high-pressure arrest situations. Ergonomics 60(5):1-11. https://doi. org/10.1080/00140139.2016.1205222

Renshaw I, Moy B (2018) A constraint-led approach to coaching and teaching games: can going back to the future solve the «they need the basics before they can play a game» argument? Ágora Para La Educación Física y El Deporte 20(1):1-26. https://doi.org/10.24197/aefd.1.2018.1-26 
Renshaw I, Davids K, Araújo D, Lucas A, Roberts WM, Newcombe DJ, Franks B (2019) Evaluating weaknesses of "perceptual-cognitive training" and "brain training" methods in sport: an ecological dynamics critique. Front Psychol 9:245. https://doi.org/10.3389/fpsyg.2018.02468

Rutter M (2020) Resilience in the face of adversity. Br J Psych 147(6):598-611. https://doi.org/10.1192/ bjp.147.6.598

Schöllhorn W (1999) Individualität: ein vernachlässigter Parameter? Leistungssport 2:7-12

Schöllhorn W, Hegen P, Davids K (2012) The nonlinear nature of learning: a differential learning approach. Open Sports Sci J 5(1):100-112

Seifert L, Papet V, Strafford BW, Coughlan EK, Davids K (2019) Skill transfer, expertise and talent development: an ecological dynamics perspective. Movem Sport Sci Sci Motricité 19(6):705-711. https://doi.org/10.1051/sm/2019010

Shipton B (2012) Expanding police educators' understanding of teaching, are they as learner-centred as they think? J Learn Des 4(2):1-19. https://doi.org/10.5204/jld.v4i2.71

Sjöberg D, Karp S (2012) Video-based debriefing enhances reflection, motivation and performance for police students in realistic scenario training. Proced Soc Behav Sci 46:2816-2824. https://doi.org/ 10.1016/j.sbspro.2012.05.570

Sjöberg D, Karp S, Rantatalo O (2016) Acting in scenario training as a tool for developing professional knowing in police education. Nordic Police Research Seminar 2016: (Police) Reforms and Changes in the Police.

Staller MS, Körner S (2018) Your partner makes you better: the partner interaction paradigm in conflict training. Movem J Phys Edu Sport Sci 11(3):169

Staller MS, Körner S (2019a) Commentary: complex motor learning and police training: applied, cognitive, and clinical perspectives. Front Psychol 10:2444. https://doi.org/10.3389/fpsyg.2019.02444

Staller MS, Körner S (2019b) Quo vadis Einsatztraining? [Quo vadis police training?]. In: Kühne E (ed) Die Zukunft der Polizeiarbeit - die Polizeiarbeit der Zukunft - Teil II, pp 321-364. Eigenverlag der Hochschule der Sächsischen Polizei (FH).

Staller MS, Zaiser B (2015) Developing problem solvers: new perspectives on pedagogical practices in police use of force training. J Law Enforce 4(3):1-15

Staller MS, Bertram O, Körner S (2017a) Weapon system selection in police use-of-force training: value to skill transfer categorisation matrix. Salus J 5(2):1-15

Staller MS, Zaiser B, Körner S (2017b) From realism to representativeness: changing terminology to investigate effectiveness in self-defence. Mart Arts Stud 4:70-77. https://doi.org/10.18573/j.2017. 10187

Staller MS, Koerner S, Heil V, Abraham A, Poolton J (2021). Police recruits ‘ wants and needs in police training in Germany. Under Review.

Thomas G (2011) A typology for the case study in social science following a review of definition, discourse, and structure. Qualit Inquiry 17(6):511-521. https://doi.org/10.1177/1077800411409884

Todak N, James L (2018) A systematic social observation study of police de-escalation tactics. Police Quart 18(2):109861111878400. https://doi.org/10.1177/1098611118784007

Todak N, White MD (2019) Expert officer perceptions of de-escalation in policing. Policing 36(1):47. https://doi.org/10.1108/pijpsm-12-2018-0185

van der Mars H (2006) Time and learning in physical education. In: Kirk D, Macdonald D, Osullivan M (eds) The handbook of physical education, pp 191-213. Routledge.

Werth EP (2011) Scenario training in police academies: developing students' higher-level thinking skills. Police Pract Res 12(4):325-340. https://doi.org/10.1080/15614263.2011.563970

Zaiser B, Staller MS (2015) The word is sometimes mightier than the sword: Rethinking communication skills to enhance officer safety. J Law Enforce 4(5):1-17

Publisher's Note Springer Nature remains neutral with regard to jurisdictional claims in published maps and institutional affiliations. 


\section{Authors and Affiliations}

Mario S. Staller ${ }^{1}[1] \cdot$ Swen Koerner ${ }^{2} \cdot$ Valentina Heil $^{3} \cdot$ Isabel Klemmer ${ }^{1}$. Andrew Abraham ${ }^{4}$. Jamie Poolton ${ }^{4}$

1 Department of Police, University of Applied Sciences of Police and Public Administration North Rhine-Westphalia, Aachen, Germany

2 Department of Training Pedagogy and Martial Research, German Sports University, Cologne, Germany

3 Department of Psychological Sciences, University of Liverpool, Liverpool, UK

4 Carnegie School of Sport, Leeds Beckett University, Leeds, UK 